\title{
Ebelik Öğrencilerinin İlk Klinik Deneyim Başlangıcı ve Sonunda Anksiyete ve Stres Düzeylerinin Belirlenmesi
}

\section{The Determination of Anxiety and Stress Levels of Midwifery Students Begining the First Clinical Experience and Post-Experience Period}

\author{
Yasemin AYDIN KARTAL ${ }^{a}$ iD, Saadet YAZICI $^{\mathrm{b}}$ iD
}

\begin{abstract}
ÖZET Amaç: Bu çalışma ebelik birinci sınıf öğrencilerinin ilk klinik deneyim başlangıcı ve sonunda yaşadıkları klinik stres düzeyleri, durumluluk-sürekli kaygı düzeyleri ve etkileyen faktörleri belirlemek amacıyla yürütüldü. Yöntem: Tanımlayıcı ve analitik desende yürütüldü. Bir kamu üniversitesinin Sağlık Bilimleri Fakültesi Ebelik Bölümü birinci sınıf öğrencileri (75) çalışmanın evreni oluşturdu. Çalışmada örneklem seçimine gidilmedi ve çalışmaya katılmayı kabul eden 70 öğrenci çalışmanın örneklemini oluşturdu (Katılma Oranı: \%93). Veriler, "Kişisel Bilgi Formu", "Klinik Stres Anketi”, "Durumluluk-Sürekli Kaygı Envanteri” ile toplandı. Bulgular:

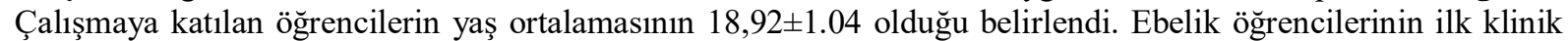
uygulama başlangıcında yaşadıkları stres düzeyleri, sonrasına göre anlamlı olarak yüksek bulunurken, klinik uygulama başlangıcı ve sonrasında en fazla stresin mücadele alt boyutunda yaşandığı belirlendi. Bununla birlikte öğrencilerin bildirdiği stres faktörleri arasında hastaya zarar verme korkusu ve klinik hekim-hemşirelerinin tutumlarının ilk sıralarda yer aldığı saptandı. Klinik uygulama başlangıcı öğrencilerin durumluluk-sürekli kaygı puan ortalamaları klinik uygulama sonrasına göre anlamlı olarak yüksek bulundu. Ebelik bölümünü isteyerek seçen öğrencilerin durumluluk kaygı düzeyleri ve sağlık meslek lisesi mezunu olan öğrencilerin stres düzeyleri ve durumluluk kaygı düzeyleri anlamlı olarak düşük bulundu. Sonuç: Öğrencilerin durumluluk-sürekli kaygı ve stres düzeyleri ilk klinik deneyim sırasında yükselirken, klinik deneyim artıkça kaygı ve stres düzeylerinin azaldığı söylenebilir
\end{abstract}

Anahtar Kelimeler: Klinik uygulama, anksiyete, ebelik

\begin{abstract}
Objective: This study is conducted to determine the factors affecting the anxiety and stress levels of first year midwifery students begining and after their first clinical experience. Method: This descriptive and analytical study used a popultaion of 75 students studying in the first grade of the midwifery department of the Health Sciences Faculty of a public university. Sample selection was not made in the study, and 70 students who agreed to participate in the study constituted the sample of the study (participation rate: 93\%). The data were collected by "Personal Information Form", "Clinical Stress Questionnaire", "State-Trait Anxiety Inventory". Results: The average age of students participating in the study was determined as $18.92 \pm 1.04$. The levels of stress begining the first clinical applications of midwifery students were higher than later. Among the stress factors reported by the students were the fear of harm to the patient and the attitudes of the clinical physician-nurses. The state of the state-trait anxiety scores of the clinical application order was found to be significantly higher than that of the post clinical application. The state anxiety levels of students who voluntarily selected midwifery department and the stress level and state anxiety levels of students graduated from health vocational high school were found to be significantly lower. Conclusions: It has been found that, the state-trait anxiety and stress levels of the students rise begining their first clinical experience. Additionally, as the stundets' clinical experience increase, their stress levels decrease.
\end{abstract}

Key words: Clinical practice, anxiety, midwifery

\section{Giriş}

Ebelik eğitiminde temel amaç, öğrenciye bilişsel, duyuşsal ve psikomotor alanda bilgi, beceri ve tutum kazandırmaktır. Ebelik eğitimi, teorik ve

klinik olmak üzere birbirini tamamlayan iki bölümden oluşur. Klinik eğitim, öğrencinin gerçek ortamda uygulayarak öğrenmesini sağlar.

Geliş Tarihi/Received: 14-07-2017 / Kabul Tarihi/Accepted:25-08-2017

a Yard. Doç. Dr. Sağlık Bilimleri Üniversitesi, Sağlık Bilimleri Fakültesi, Ebelik Bölümü, Istanbul: ORCID

ID:orcid.org/0000-0001-7464-945X

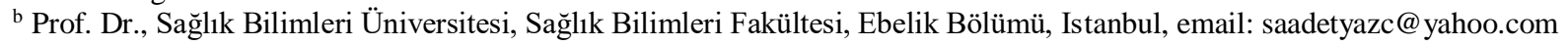
ORCID ID: orcid.org/0000-0001-6348-0695

Sorumlu yazar /correspondence: Yasemin Aydin Kartal; Sağlık Bilimleri Üniversitesi, Sağlık Bilimleri Fakültesi, Ebelik Bölümü, Yrd.Doç.Dr, e-mail: yasemin.aydin@sbu.edu.tr

*Çalışma Adnan Menderes Üniversitesi 1. Uluslararası Sağlık Bilimleri Kongresi’nde Sözel bildiri olarak sunulmuştur. 
Klinik deneyimler, teorik bilginin uygulamaya aktarılmasının yanı sıra öğrencinin psikomotor gelişimini ve mesleki sosyalizasyonunu sağlar. ${ }^{1}$ Klinik deneyimleri süresince yeni bir sosyal ortama giren öğrenciler çeşitli aşamalarda, anksiyete ve stres yaratan çok sayıda durumla baş etmek zorunda kalır. Anksiyete ve stres eğitim süresince ögrencinin akademik performansını ve mesleki uyumunu etkileyen önemli bir biyopsikososyal faktördür. ${ }^{2}$ Düşük düzeyde stres ve kayg1, öğrencilerin yaratıcılığına ve gelişimine katkı sağlarken, stres ve kayg1 yoğun olduğunda öğrenme güçlüğü yaşamaya, dikkat ve yoğunlaşmada azalmaya, insan ilişkilerinde bozulmaya ve iş veriminde azalmaya neden olmaktadır. ${ }^{1,3}$

Klinik uygulamalarda öğrencilerin yaşadığ 1 stres ve anksiyete, öğrendikleri kuramsal bilgilerin kullanılmasında güçlüğe neden olmaktadır. Ayrıca sağlık profesyonelleri ile iletişim güçlügü yaşanmasına, hata yapma korkusuna, hastaya yanlış bilgi verme endişesine, hasta beklentilerini karşılamada eksikliğe, hastane prosedürlerinde yanlış yapma korkusuna ve mesleki yetersizliğe neden olduğu bildirilmektedir. ${ }^{4,5}$

Özellikle ilk klinik deneyim öngörülmez ve zorlayıcı olmasından dolayı daha çok anksiyete ve stres oluşturabilmektedir. Öğrenciler tehdit ve tehlike olarak algıladıkları ve bu durum karşısında dengeyi korumak veya dengeyi yeniden sağlamak için çalışırken stresi deneyimleyebilmektedirler. ${ }^{6}$

Anksiyeteli ve stresli öğrenci, problemlerle baş etme yeteneğinde ve sosyal ilişkilerde azalma yaşayabilmektedir. Ayrıca stresin öğrencinin beceri geliştirme ve klinik performansını etkilediği düşünülmektedir. Bu sebeple öğrencilerin klinik öğrenme deneyimlerinin her aşamasında anksiyete ve stres düzeyleri ve etkileyen faktörlerin belirlenmesi ayrıca önem taşımaktadır. Dolayısıyla, bu çalışma, öğrencilerin klinik deneyimleri süresince yaşadıkları stres, anksiyete düzeyi ve neden olan faktörlerin belirlenmesi, öğretim üyelerinin öğrencilerin stresle başetmede strateji geliştirmelerine yardımcı olmak amaciyla yürütülmüştür.

\section{Gereç ve Yöntem \\ Araştırmanın Evreni ve Örneklemi: Tanımla- yıcı ve analitik desende yürütülen çalışmanın ev- renini, bir kamu üniversitesinin, Sağlık Bilimleri Fakültesi, Ebelik Bölümü birinci sınıfta öğrenim gören 75 öğrenci oluşturdu. Çalışmada örneklem seçimine gidilmedi ve 2016-2017 eğitim-öğretim dönemi bahar yarıyılında çalışmaya katılmayı ka- bul eden 70 öğrenci çalışmanın örneklemini oluş- turdu (Katılma Oranı: \%93).}

Tablo 1. Öğrencilerin KSA Toplam ve Alt Boyut Puan Ortalamalarının Dağılımı

\begin{tabular}{lllll}
\hline Ölçek Boyutları & $\begin{array}{c}\text { Klinik Deneyim } \\
\text { Başlangıcında } \\
\text { Ort } \pm \text { SS }\end{array}$ & $\begin{array}{c}\text { Klinik Deneyim } \\
\text { Sonunda } \\
\text { Ort } \pm S S\end{array}$ & Puan Aralığ1 & Test \\
\hline Tehdit alt boyutu & $6.94 \pm 4.35$ & $5.48 \pm 3.81$ & $0-24$ & $\mathrm{z}^{*}:-2.501 \mathrm{p}: 0,012$ \\
Mücadele alt boyutu & $16.04 \pm 5.03$ & $13.28 \pm 5.60$ & $0-28$ & $\mathrm{z}^{*}:-3.698 \quad \mathrm{p}: 0,000$ \\
Zarar alt boyutu & $3.05 \pm 2.72$ & $1.94 \pm 2.00$ & $0-20$ & $\mathrm{z}^{*}:-3.403 \mathrm{p}: 0,001$ \\
Yarar alt boyutu & $4.58 \pm 1.80$ & $3.30 \pm 2.15$ & $0-8$ & $\mathrm{z}^{*}:-4.483 \mathrm{p}: 0,000$ \\
Toplam ölçek puanı & $30.62 \pm 9.6$ & $24.01 \pm 8.63$ & $0-80$ & $\mathrm{z}^{*}:-5.101 \mathrm{p}: 0,000$ \\
\hline
\end{tabular}

*Wilcoxon Signed Ranks Test

Veri Toplama Araçları: Araştırma verilerinin toplanmasında "Kişisel Bilgi Formu", "Klinik Stres Anketi" ve "Durumluluk-Sürekli Kayg1 Envanteri" kullanıldı. Kişisel Bilgi Formu'nda, araş tırmacılar tarafindan literatür taranarak geliştirilen, öğrencilerin sosyo-demografik özelliklerine ilişkin sorular yer aldı.

Klinik Stres Anketi (KSA): Klinik stres anketi, ilk klinik uygulama deneyimlerinde, ögrenci hemşireleri tehdit eden ya da mücadele etmelerini gerektiren stresin başlangıç değerini be lirmek amacıyla Pagana tarafından geliştirilmiştir. ${ }^{7}$ Ölçek likert tipi olup 20 maddeden oluşmaktadır. Ölçeğin maddeleri; tehdit, mücadele, zarar ve yarar duygu ifadelerinden oluşan 4 alt başlık altında toplanmaktadır. Ölçeğin puan aralı̆̆ $0-80$ dir. Düşük puan stres düzeyinin düşük olduğunu, yüksek puan ise stres düzeyinin yüksek olduğunu ifade etmektedir. Klinik Stres Anketi'nin geçerlilik ve güvenirliliği Şendir ve Acaroğlu (2008) tarafından yapılmıştır. ${ }^{1} \mathrm{Bu}$ çalışmanın örneklemi için toplam Cronbach alfa değeri klinik uygulama 
başlangıcı 0.74 , sonrası için 0.81 olarak bulunmuştur.

Durumluk-Sürekli Kaygı Envanteri: Spielberger ve arkadaşları (1970) tarafından geliştirilen ölçeğin Türk toplumunda geçerlik ve güvenirliği Öner ve Le Compte (1977) tarafindan yapılmıştır. ${ }^{8,9}$ Ölçek geçici-durumluk (20 madde) ve sürekli (20 madde) kayg1 düzeylerini belirleyen toplam 40 maddeden oluşmaktadır. Durumluk Kayg1 Envanteri (DKE), bireyin belirli bir anda ve belirli koşullarda kendisini nasıl hissettiğini ve Sürekli Kayg1 Envanteri (SKE)'de, bireyin kendisini genellikle nasıl hissettiğini değerlendirmektedir. Puanların artması kaygı düzeyinin yüksek olduğuna işaret etmektedir. Bu çalışmanın örneklemi için DKE'nin toplam Cronbach alfa değeri klinik uygulama başlangıcı 0.74, sonrası için 0.81, SKE'nin ise klinik uygulama başlangıcı 0.72 , sonrası için 0.71 olarak bulunmuştur.

Araştırmanın verileri, çalışmayı yürüten araştırmacılar tarafindan, çalışmaya katılmayı kabul eden öğrencilerle yüz yüze görüşme tekniği uygulanarak toplandı. Formların uygulanması yaklaşık 20 dakika sürdü. Formlar öğrencilere klinik uygulamaya çıkılan ilk haftanın sonunda ve klinik uygulamanın son haftasında uyguland.

Verilerin Değerlendirilmesi: Veriler, SPSS 17.0 paket programı kullanılarak tanımlayıc istatistiksel analizlerinden sayı, yüzde, ortalama ve standart sapma ile hesaplandı. Verilerin dağılımı Kolmogorov Smirnov testi ile değerlendirildi. Gruplar aras1 karşılaştırmalar Mann Whitney U test, Kruskal Wallis Test ve Wilcoxon Signed Ranks Test kullanılarak değerlendirildi. 0.05 in altındaki " $p$ " değerleri istatistiksel olarak anlamlı kabul edildi.

Araştırmanın Etik İlkeleri: Araştırmanın yapıldığı kamu üniversitesinin Sağlık Bilimleri Fakültesi'nden yazılı izin alındı. Araştırmaya alınacak öğrencilere çalışma hakkında bilgi verildikten sonra öğrencilerin sözel izinleri alındı. Araştırmaya katılacak öğrencilere, bireysel bilgilerin gizli kalacă̆ 1 konusunda açıklama yapılıp "gizlilik ilkesine" uyulmuştur.

Araştırmanın Sınırlılıkları: Çalışmanın sınırlılığ sadece bir kamu üniversitesinin ebelik bölümü öğrencileri ile yürütülmesidir. Bu nedenle bu bulgular Türkiye'deki tüm Ebelik bölümü öğrencileri için genellenemez.

\section{Bulgular}

Çalışmaya dahil edilen öğrencilerin yaş ortalama-

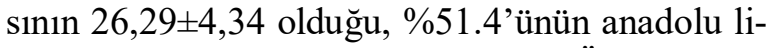
sesi mezunu olduğu belirlendi. Öğrencilerin \%75.7'sinin bölümü isteyerek tercih ettiğini, \%92.9'unun ebelik mesleğini sevdiğini ve kendisini mesleğe uygun hissettiğini ifade etti. Öğrencilerin ilk klinik deneyim sırasinda ne hissettikleri sorulduğunda ise $\% 65,7$ 'si heyecan, \%54.3'ü mutluluk, \%47.1'i stres, \%35.7'si anksiyete ve \%18.6'sının korku hissettiği belirlendi.

Ebelik öğrencilerinin ilk kez klinik uygulama başlangıcındaki stres düzeyleri, sonrasına göre anlamlı olarak yüksek bulunurken, klinik uygulama başlangıcında ve sonrasında en fazla stresin mücadele alt boyutunda, en düşük stresin ise zarar alt boyutunda yaşandığı belirlendi (Tablo 1).

Öğrencilerin klinik uygulama başlangıcı durumluluk kaygı puan ortalamaları $37.37 \pm 8.81$, klinik uygulama sonras1 35.01 \pm 7.48 iken (z:-2.037, p:,042), klinik uygulama başlangıcı sürekli kaygı puan ortalamaları $41.80 \pm 6.50$, klinik uygulama sonras1 ise $37.45 \pm 6.63$ (z:-5,756, p:,000) olduğu belirlendi (Tablo 2).

Ebelik bölümünü isteyerek seçen öğrencilerin durumluluk kaygı düzeyleri (z:-2.752, p:,006) ve sağlık meslek lisesi mezunu olan öğrencilerin stres düzeyleri (z:8,019, p: ,018) ve durumluluk kayg1 düzeyleri (z:9.857:, p:,007 ) anlamlı olarak düşük bulundu. Öğrencilerin klinik uygulama sırasında bildirdiği stres faktörleri arasında, hastaya zarar verme korkusu(\%58,6), hekim ve ebe-hemşirelerin tutumları $(\% 47,1)$ ve hastane prosedürlerinde yanlış yapma korkusu(\%42,9) ilk siralarda yer aldığı belirlendi (Tablo 3).

Tablo 2. Öğrencilerin DKE-SKE Toplam Ortalamalarının Dağılımı

\begin{tabular}{llll}
\hline & $\begin{array}{l}\text { Klinik Deneyim Baş- } \\
\text { langıcında Ort } \pm \text { SS }\end{array}$ & $\begin{array}{l}\text { Klinik Deneyim } \\
\text { Sonunda } \\
\text { Ort } \pm \text { SS }\end{array}$ & Test \\
\hline Durumluluk Kaygı Envanteri & $37.37 \pm 8.81$ & $35.01 \pm 7.48$ & $\mathrm{z}^{*}:-2.037$ p:0,042 \\
Sürekli Kaygı Envanteri & $41.80 \pm 6.50$ & $37.45 \pm 6.63$ & $\mathrm{z}^{*}:-5,756$ p:0,000 \\
\hline
\end{tabular}

*Wilcoxon Signed Ranks Test 
Tablo 3. Öğrencilerin Klinik Uygulamada Bildirdikleri Stres Faktörleri

\begin{tabular}{lcl}
\hline & $\mathbf{n}$ & $\mathbf{\%}$ \\
\hline Hastaya zarar verme korkusu & 41 & 58,6 \\
Hekim ve ebe-hemşirelerin tutumları & 33 & 47,1 \\
Hastane prosedürlerinde yanlış yapma korkusu & 30 & 42,9 \\
Teorik bilgiyi uygulayamama & 28 & 40.0 \\
Hastaya yanlış bilgi verme korkusu & 21 & 30.0 \\
Öğrenci ebeye güvensizlik & 19 & 27,1 \\
Hata yapma korkusu & 17 & 24,3 \\
\hline
\end{tabular}

\section{Tartışma}

$\mathrm{Bu}$ çalışma, ebelik birinci sınıf öğrencilerinin ilk klinik deneyim başlangıcı ve sonrası yaşadıkları klinik stres düzeyleri, durumluluk-sürekli kaygı düzeyleri ve etkileyen faktörleri belirlemek amacıyla yürütüldü. Bulgularımızda öğrencilerin durumluluk-sürekli kaygı ve stres düzeyleri ilk klinik deneyim sırasında yükselirken, klinik deneyim artıkça kaygı ve stres düzeylerinin azaldığı belirlendi (Tablo 1-2). Klinik uygulama sirası ve sonrasinda en fazla stresin mücadele alt boyutunda yaşandığı belirlenirken, en düşük stresi ise zarar alt boyutunda yaşadıkları belirlendi (Tablo 1). Çalışmamızla benzer şekilde Mankan ve ark. (2016)'1 çalışmalarında en yüksek stresin mücadele alt boyutunda, en düşük stresin zarar alt boyutunda yaşandığını, Taşdelen ve Zeybek (2013) ise çalışmalarında öğrencilerin en yüksek stresi mücadele, en düşük stresi ise yarar alt boyutunda yaşadıklarını bildirmişlerdir. ${ }^{10,11}$ Çalışmamızdan farklı olarak Atay ve Y1lmaz (2011)'ın çalışmasinda öğrencilerin tehdit ve zarar alt boyutunda yüksek düzeyde klinik stres yaşadıkları belirlenmiştir. ${ }^{12}$ Farklı çalışma sonuçları, çalışmaların yapıldığ 1 okullardaki müfredat farklılıkları, öğretim elemanı sayıları ve uygulamaya çıkılan hastanelerin farklı olmasından kaynaklanabilir.

Öğrencilere yaşadıkları klinik deneyim s1rasinda ne hissettikleri sorulduğunda \%35.7'si anksiyete ve \%18.6'sı korku yaşadıklarını belirttiler. Anksiyete, korku gibi duygular karşısında organizmanın yeniden dengeyi sağlamak adına yaşadığ 1 stres algısının öğrencilerin işlevselliği ve problem çözme becerisini olumsuz etkilediği bildirilmektedir. ${ }^{13} \mathrm{Bu}$ bağlamda ilk klinik deneyim öncesinde öğrencilerin yakından değerlendirilmesi, korkan, kayg1 duyan, heyecanlı olan öğrencilerin riskli grup olarak değerlendirilmesi ve des tek sağlanması önerilmektedir. Ayrıca bu duyguların altında yatan düşüncelere yönelik farkındalık sağlanması büyük önem taşımaktadır.

Ebelik bölümünü isteyerek seçen öğrencilerin durumluluk kaygı düzeyleri ve sağlık meslek lisesi mezunu olan öğrencilerin stres düzeyleri ve durumluluk kaygı düzeyleri anlamlı olarak düşük bulunmuştur. Mesleği sevmeme, rastgele seçme, ilgisiz olma bireyin motivasyonunu etkileyen önemli faktörlerdir. Motivasyonun düşük olması bireyin öğrenmeye uyum sağlayamamasına ve bu durumda dış dünyayı tehlikeli ve tehdit edici bir yer olarak algılayıp kaygısının yükselmesine neden olabilir. Bu nedenle çalışmamızda ebelik bölümünü isteyerek seçen öğrencilerin durumluluk kaygı düzeylerinin düşük olması literatürdeki bilgiyi destekler niteliktedir. Sağlik meslek lisesi mezunu öğrencilerin stres düzeyleri ve durumluluk kaygı düzeylerinin düşük olması deneyimle ilişkilendirilebilir. Nitekim çalışmamızın bulgularında da deneyim artıkça stres ve kaygı̈ düzeyinin azaldığı saptanmıştır.

Öğrencilerin klinik uygulamada bildirdikleri stres faktörleri arasında en yüksek oranda hastaya zarar verme korkusu olduğu ve bunu sirasıyla hekim, ebe ve hemşirelerin tutumlarının ve hastane prosedürlerinde yanlış yapma korkusunun takip ettiği belirlendi (Tablo 3). Mangan ve arkadaşlarının (2016) çalışmasında öğrencilerin en çok hastalardan dolayı stres yaşadıkları, Taşdelen ve Zeybek (2013)'in çalışmasında ise en çok hemşirelerin öğrenciler için stres kaynağı oluşturduğu, Elçigil ve Sarı (2011)'nın çalışmasında ise klinik çalışanlarının öğrencilere karşı tutumları olarak belirtmiştir. ${ }^{10,11,14}$ Uygulama yapılan kliniklerde görevli hekim, ebe ve hemşirelerin mesleki yönden donanimlı ve olumlu rol modeli olması uygulama he 
deflerine ulaşılması açısından önemlidir. ${ }^{15}$ Uygu lamalar sırasında öğrencinin yönlendirilmeye, desteklenmeye ve bu desteği hissetmeye ihtiyacı vardır. Bu çalışma sonuçlarından yola çıkarak öğrenci ebelerin klinik uygulama öncesi klinikteki görevli hekim, ebe ve hemşirelerle tanıştırılması, kliniğin fiziksel yapısı, kurallar ve öğrencilerden beklentiler ile ilgili olarak öğrencilerin bilgilendirilmesi sağlanmalıdır.

\section{Sonuç ve Öneriler}

Araştırmadan elde edilen sonuçlara göre, öğrencilerin durumluluk-sürekli kaygı ve stres düzeyleri ilk klinik deneyim sırasında yükselirken, klinik deneyim artıkça kayg1 ve stres düzeylerinin azaldığ 1 belirlendi. Ebelik bölümünü isteyerek seçen ögrencilerin durumluluk kaygı düzeyleri ve sağlı meslek lisesi mezunu olan öğrencilerin stres düzeyleri ve durumluluk kaygı düzeyleri anlamlı olarak düşük olduğu saptandi. Klinik uygulamada öğrencilerin en büyük stres kaynağının hastaya zarar verme korkusu ve hekim, ebe-hemşirelerin tutumları olduğu belirlendi.

$\mathrm{Bu}$ sonuçlar doğrultusunda, klinik öğretim öncesinde simülasyon teknikleri kullanılarak oluşturulan klinik ortama benzer öğretim alanlarında ögrencilerin kliniğe kendilerini daha hazır hissetmelerinin sağlanması, kliniğin fiziksel yapısı, klinik ekibi, kurallar ve öğrenciden beklentiler konusunda öğrencilerin bilgilendirilmesi, ilk klinik deneyim öncesinde öğrencilerin yakından değerlendirilmesi, korkan, kaygı duyan, heyecanlı olan öğrencilerin riskli grup olarak değerlendirilmesi ve ayrıca destek sağlanması önerilebilir.

\section{Kaynaklar}

1. Şendir M, Acaroğlu R. Reliability and Validity of Turkish Version of Clinical Stress Questionnaire. Nurs Educ Today 2008; 28(6): 737-43.

2. Jimenez C, Navia-Osorio P, Vacas Diaz C. Stress and Health in Novice and Experienced Nursing Students. Journal of Advanced Nursing 2010; 66 (2): 442-455.

3. Lee J, Graham AV. Student's Perception of Medical School Stress and Their Evaluation of A Welness Elective. Medical Education 2001; 35: 652-659.

4. Sheu S, Lin HS, Hwang SL. Perceived Stress and Physio-Psycho-Social Status of Nursing Students During Their Initial Period of Clinical Practice: The Effect of Coping Behaviors. International Journal of Nursing Studies 2002; 39 (2): 165-175.
5. Sharif F, Masoumi S. A Qualitative Study of Nursing Student Experiences of Clinical Practice. BMC Nurs 2005; 4(6): 1-7.

6. Balcıŏlu İ. Stres Kavramı ve Tarihsel Gelişimi. Medikal Açıdan Stres ve Çareleri [Concept of Stress and Historical Development. Medical Stress and Remedies]. Sempozyum Dizisi [Symposium series] 2005; 47: 09-12.

7. Pagana KD. Psychometric Evaluation of Clinical Stress Questionnaire (CSQ). J Nurs Educ 1989;28(4):169-74.

8. Spielberger CD, Gorsuch RL, Lushene RE. Manual for Stait-Trait Anxiety Inventory, Consulting Psychologist Press. California: 1970.

9. Öner N, Le Compte A. Durumluk-Sürekli Kayg1 Envanteri El Kitab1. [Handbook of State-Trait Anxiety Inventory] İstanbul: Boğaziçi Üniversitesi Yayınları; 1983.

10. Mankan T, Polat H, Cengiz H, Sevindik F. Hemşirelik Öğrencilerinin İlk Klinik Stres Düzeyleri ve Etkileyen Faktörlerin Belirlenmesi [The First Clinical Stress Level of the Nursing Students and the Factors Affecting]. İnönü Üniversitesi Sağlık Bilimleri Dergisi [Journal of İnönü University Health Sciences] 2016; 5 (1): 10-15

11. Taşdelen S, Zaybak A. Hemşirelik Öğrencilerinin İlk Klinik Deneyim Sirasındaki Stres Düzeylerinin İncelenmesi [The Determination The Level of Stress of Nursing Students During Their First Clinical Experience]. Florence Nightingale Hemşirelik Dergisi [Florence Nightingale Journal of Nursing] 2013; 21(2): 101-06.

12. Atay S, Yılmaz F. Sağlık Yüksek Okulu öğrencilerinin ilk klinik stres düzeyleri [The First Stress Levels of The Students of Vocational Higher School of Health] Anadolu Hemşirelik ve Sağlık Bilimleri Dergisi [Journal Of Anatolia Nursing And Health Sciences] 2011; 14 (4): 32-37.

13. Arabac1 LB, Korhan EA, Tokem Y, Torun R. Hemşirelik Birinci Sınıf Öğrencilerinin İlk Klinik Deneyim Öncesi-Sırası ve Sonras1 Anksiyete ve Stres Düzeyleri ve Etkileyen Faktörler [Nursing Students' Anxiety And Stress Levels And Contributed Factors Before-During And After First Clinical Placement]. Hacettepe Üniversitesi Hemşirelik Fakültesi Dergisi [Hacettepe University Faculty of Health Sciences Nursing Journal] 2015;116. 
14. Elçigil A, Sarı HY. Hemşirelik Öğrencilerinin Klinik Eğitiminde Kolaylaştırıcı Faktörler [Facilitating Factors in Clinical Education in Nursing]. Dokuz Eylül Üniversitesi Hemşirelik Yüksekokulu Elektronik Dergisi [Dokuz Eylül University Faculty of Nursing Electronic Journal] 2011; 4(2): 67-71.

15. Erenel AŞ, Dal Ü, Kutlutürkan S, Vural G. Hemşirelik Dördüncü Sınıf Öğrencilerinin ve Hemşirelerin İntörnlük Uygulamasına İlişkin Görüşleri [The Views of the Fourth Year Students and Nurses About Internship Practices]. H.Ü. Sağlık Bilimleri Fakültesi Hemşirelik Dergisi [Hacettepe University Faculty of Health Sciences Nursing Journal] 2008; 15(2):16-25. 